\author{
EVS25 \\ Shenzhen, China, Nov 5-9, 2010
}

\title{
Sizing and fuel consumption evaluation methodology for hybrid light duty vehicles
}

\author{
Nicolas Marc ${ }^{1,3}$,Eric Prada ${ }^{1}$, Antonio Sciarretta ${ }^{2}$, Shadab Anwer ${ }^{1}$, Franck Vangraefschepe ${ }^{2}$, \\ François Badin ${ }^{1}$, Alain Charlet ${ }^{3}$, Pascal Higelin ${ }^{3}$ \\ ${ }^{1}$ IFP Energies nouvelles, Rond-point de l'échangeur de Solaize, BP 3, 69360 Solaize, France \\ (nicolasmarc.fr@ifpen.fr) \\ ${ }^{2}$ IFP Energies nouvelles, 1 et 4 avenue de Bois-Préau, 92852 Rueil-Malmaison, France \\ ${ }^{3}$ PRISME/EPM, Université d'Orléans, 8 rue Léonard de Vinci, 45072 Orléans Cedex 2, France
}

\begin{abstract}
This paper presents a methodology dedicated to component sizing and fuel consumption evaluation of different degree of hybridization for light duty vehicles applications. The methodology will be described together with vehicle and components simulation and sizing principles. To ensure a systematic approach, with no bias for any of the cases considered, the energy management of the hybrid drivetrain will be carried out thanks to an optimization based on the Pontryagin's Minimum Principle. As hybrid fuel consumption is highly dependant on vehicle type of use, the hybrid vehicles will be evaluated on different actual use driving patterns as well as on missions representing the daily usage of the vehicle. The methodology and a panel of results are presented in the paper.
\end{abstract}

Keywords: HEV, plug-in HEV, components sizing, energy consumption, simulation, optimized energy management

\section{Introduction}

HEVs are complex systems in which many parameters could impact the fuel economy potential and it appears that car and component manufacturers are unveiling various types of architectures (Toyota, Honda, GM, BMW, Daimler, Nissan, PSA, BYD...).

Therefore, to compare these different solutions on a same basis, a comprehensive approach to predimension and assess hybrid-electric powertrain architectures energy efficiency potential is necessary. Such methodology will be presented in the paper with results illustrating various degree of hybridization for a parallel architecture for a light duty vehicle, according to their type of use.

The developed approach consists of:

1. a method dedicated to the sizing of the vehicle components, with respect to the Program of Demand, and to the generation of map representations of the differently sized components (battery, electric machine, IC engine, etc.);

2. a method to compute the optimal vehicle energy management (torque, speed, power) as a function of time for a given drive cycle, based on optimal control theory and Pontryagin's Minimum Principle.

The vehicle considered in our evaluation is a passenger car in the low-mid range group.

\section{Powertrain requirements and components sizing}

\subsection{Drivetrain architectures}

Two different hybrid configurations were considered, both of them based on the same architecture (parallel pre-transmission) but with different functionalities, i.e.: 
- parallel full hybrid operating in Charge Sustaining mode (HEV CS);

- parallel plug in full hybrid (PHEV) operating in Charge Depleting (CD) mode and implementing two different strategies i.e.:

o A blended type strategy for all areas where the use of the IC engine is allowed, this mean that the IC engine will be used to cover the vehicle dynamic performances, in cooperation with the electric chain if required by the driving conditions. This strategy has the advantage to reduce the constraints on the battery pack and electric machine sizing, as far as maximum peak power is concerned;

o An all electric mode for specific inner urban areas where the IC engine would be prohibited, corresponding to an UrbanCapable PHEV [1]. The electric chain will then have to be sized according to the specified driving conditions for its maximum power, the battery energy being a consequence of the requested All Electric Range (AER);

The hypothesis together with the methodology used is described in the following chapter.

\subsection{Sizing Methodology of the Powertrain}

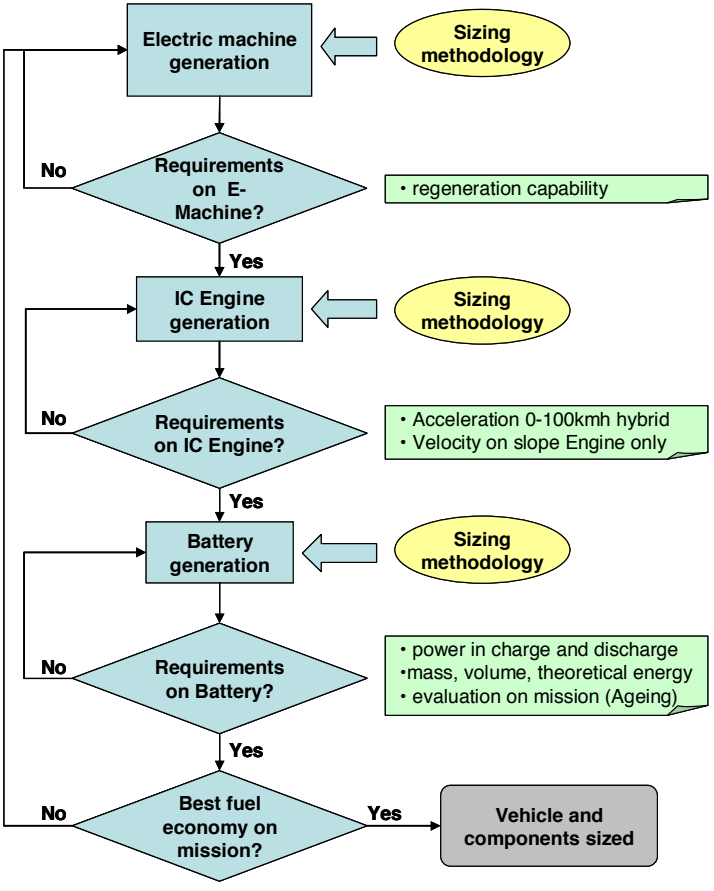

Figure 1: Sizing Workflow for the HEV CS case

\subsubsection{Dynamic performances}

The HEVs considered in this study are based on a light duty vehicle and our hypothesis is that they must fulfill the same requirements as their conventional counterpart. One could note that extra requirements, specific to hybridization, and depending on the architecture, must also be fulfilled.

For the 2 types of hybrid vehicles considered, the performances requirements must be listed as:

- Dynamic performances on a flat road, typically wide opened throttle, $0-100 \mathrm{~km} / \mathrm{h}$ or 0 $1000 \mathrm{~m}$. Such performances are usually obtained in hybrid mode, with the help of the on board energy storage system (ESS), but they should also be checked in case the ESS is fully depleted and then became of no help;

- Dynamic performances to be maintained in case of slope, typically steady speed of 110 or $130 \mathrm{~km} / \mathrm{h}$ on a $5 \%$ slope. In this case the ESS is not supposed to be involved and performances will be given by the IC engine alone for parallel architectures

For the specific PHEV case:

- Dynamic performances and range to be obtained in all electric conditions (AER). In this case the vehicle is generally operated in specific urban conditions and we considered the urban cycle generated in the frame of the European Framework Program Artemis [2]. The range will be given by the ESS total energy and by the allowed State Of Charge (SOC) window (see hereafter);

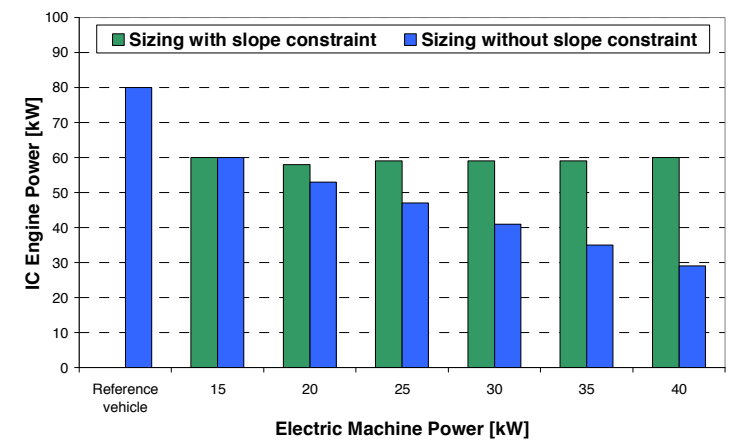

Figure 2: Effects of Program of Demand on IC engine sizing

An illustration of the IC engine sizing for the parallel full CS hybrid case is given in Figure 2. It appears that the IC engine power may be decreased according to the electric machine, power electronic and battery, size, in flat conditions, but due to the operation in case of 
slope, a minimum IC engine power must be considered (not less than $58 \mathrm{~kW}$ in the example).

The pre-dimensioning of the powertrain obtained by fulfilling all the requirements of the vehicle Program of Demand allows us to define the main characteristics of the components (peak power, energy...), the difficulty then is to get the model and the relevant data for these components. In parametric studies, linear (or homothetic-scaling) approaches are often used to define the components simulation parameters (efficiency maps for example) [3]. In this study the sizing methodology was kept simple for the IC engine and the electric machine, while a more complex approach, introducing similitude laws, was used to size the battery pack.

\subsubsection{Energy consideration}

For the CS hybrid case, the procedure described above will lead to multiple pairs of IC engine and electric machine (and corresponding battery) able to fulfil the dynamic Program of Demand, as illustrated in Figure 2. In order to make the final choice, two criteria may be used i.e.:

- consider the amount of energy available for regeneration during deceleration phases. The choice of the electric component peak power in regeneration phase may be done according to the amount of energy we want to capture. This will give us an indication of the minimum power of the electric components;

- consider the fuel consumption obtained, for each component sizing, using different vehicle driving conditions. For the application considered in this paper, we made the simulation for a commuter case with urban and road type of use, but some other specific driving patterns may be applied (urban taxi, refuse vehicle, urban buses...);

Other considerations such as battery ageing expectation and especially the SOC range allowed for operation will be taken into account in the sizing procedure.

For the CD hybrid case the distance covered by the vehicle in the $\mathrm{CD}$ mode between two charges will be a function of the total battery energy and the allowable SOC range during the operation. The allowed SOC window is of primary importance, as it will be a compromise between the battery cost and vehicle weight, if the size is too large, and the battery ageing if size is too small. PHEVs prescribed SOC windows may be found in literature, i.e. $100 \%$ to $35 \%$ in [4], close to $95 \%$ to $15 \%$ [5], $90 \%$ to $30 \%$ [6] or $85 \%$ to
$25 \%$ [1]. These values appear to be very close and consequently the SOC window considered in our evaluation was $90 \%$ to $30 \%$. Two battery sizes were then considered to cover a wide range of use, i.e. 5 and $10 \mathrm{kWh}$ of total energy.

One could note that the previous knowledge of the requested power to cope up with the AER driving schedule (see 2.2.1) will now lead to the battery Power/Energy ratio (P/E).

\subsection{IC Engine steady-state map generation}

A steady state model of a naturally aspirated gasoline IC engine using data recorded on our test bench has been created, In order to generate the efficiency maps for the different IC engines required in our procedure, a linear scaling of the consumption map and maximal torque curve were used. This approximation is reasonable as long as the power of the scaled engine is closed to the power of the original engine (in our case $80 \mathrm{~kW}$ original downsized to $59 \mathrm{~kW}$ ).

\subsection{Battery sizing problem}

Battery pack sizing for a specific vehicle usage be it $\mathrm{HEV}$, PHEV or EV is generally a rather difficult task due to a wide range of cell chemistries, and typologies. Many serial/parallel cells associations of a battery pack can fulfill power and energy requirements of vehicle use but are constrained by mass, volume, cost and ageing. The objective is to optimize the battery pack size in terms of power, energy and mass in order to respect the vehicle Program of Demand and minimize its fuel consumption.

Data sheets of commercial cells exhibiting different capacities provide power, energy and resistance values from which one can compute the $\mathrm{P} / \mathrm{E}$ ratios from high-energy cells to ultra high power cells. Similitude laws can be established from these $\mathrm{P} / \mathrm{E}$ ratios. Thanks to these laws the battery pack (voltage, capacity, power and $\mathrm{P} / \mathrm{E}$ ratio) can be sized to fit the Program of Demand. Then, one can study how the battery cell capacity and architecture impact the vehicle final fuel consumption.

For that purpose, a simple battery model derived from more complex ones, created at IFP Energies nouvelles $[7,8]$, can be calibrated for different $\mathrm{P} / \mathrm{E}$ ratios using the similitude laws. The model is a steady-state model, based on an open circuit voltage and internal resistance in charge and discharge; both of them being function of the state of charge of the battery. This model is used in our 
procedure to test different pack architectures for three main $\mathrm{P} / \mathrm{E}$ ratios and point out preferred ones as far as power, energy and mass constraints are concerned. Moreover life and cost models identified in literature or given thanks to on going programs $[9,10]$ are taken into account to refine this approach. Finally, the model can be run in a hybrid powertrain simulation platform to discuss the fuel consumption against $\mathrm{P} / \mathrm{E}$ ratios.

The battery cells used in this study were based on commercial cells of the technology Li-ion. Majoring coefficients on the internal resistance have been applied to take into account the ageing of the battery and the resistance of the connectors (respectively $20 \%$ and $10 \%$ ). A coefficient was also applied on the battery mass to consider the extra-mass of the Battery Management System (BMS), connections and cooling system (ranging from 2 to 2.5 depending on battery size).

\subsection{Electric machine steady-state map generation}

A steady-state model of the machine and the inverter has been used. The efficiencies of these two components were calculated thanks to a Park model validated on a $30 \mathrm{~kW}$ synchronous permanent magnet machine.

In order to generate the energy losses maps for the different machines required in our procedure, a linear sizing algorithm was used.

\section{Evaluation of the HEV}

\subsection{Driving Scenarios}

It is well known that the potential of a hybrid vehicle in fuel consumption reduction is highly dependent on the vehicle type of use [11, 12]. In this paper, each vehicle (sized as explained in section 2.2) will be first evaluated using actual use driving schedules issued from the European Artemis program [2]. Three different types of driving conditions (urban, road and motorway) were considered to highlight hybridization potential whereas a specific daily mission was established for the specific PHEV cases. This mission describes a daily commuting case through a succession of road, urban and road driving conditions. To access the influence of the distance driven between two charges we considered two different missions, the second being with 2 time the extra-urban distance and the same central urban part (see Table 1). A possible ZEV requirement in this central urban part of the trip may be required. For the two PHEV cases, a night charging of the battery has been considered.

Table 1: Specification of the driving schedules

\begin{tabular}{|c|c|c|c|c|c|}
\hline \multirow{2}{*}{ Cycle } & Duration & Distance & $\begin{array}{c}\text { Average } \\
\text { speed }\end{array}$ & $\begin{array}{c}\text { Max } \\
\text { speed }\end{array}$ & $\begin{array}{c}\text { Duration } \\
\text { at } \\
\text { standstill }\end{array}$ \\
\cline { 2 - 6 } & $\mathbf{s}$ & $\mathbf{k m}$ & $\mathbf{k m} / \mathbf{h}$ & $\mathbf{k m} / \mathbf{h}$ & $\mathbf{s}$ \\
\hline NEDC & 1180 & 11.0 & 33.6 & 120 & 292 \\
\hline Urban & 993 & 4.9 & 17.7 & 57.7 & 282 \\
\hline Road & 1082 & 17.2 & 57.5 & 111.5 & 33 \\
\hline Motorway & 1068 & 29.6 & 99.6 & 150.4 & 16 \\
\hline Mission 1 & 3157 & 39.4 & 44.9 & 111.5 & 348 \\
\hline Mission 2 & 5321 & 73.8 & 49.9 & 111.5 & 414 \\
\hline
\end{tabular}

\subsection{Vehicle Simulation Model}

The simulation of the vehicle dynamics and energy flows used in this study is based on a backward model. The constraints on components and energy flows are calculated from wheel to components and the components efficiencies are evaluated using steady-state maps. Regenerative braking strategies considering dynamic sharing between front and rear axles have been implemented in the vehicle model and are based on strategies defined in literature $[13,14]$.

\subsection{Energy Management System}

To compare different hybrid architectures and components sizing without any bias that may be a consequence of the use of heuristic energy management laws, the IFP's software Hybrid Optimization Tool (HOT) presented in [15] was used. This software performs the offline (i.e., drive cycle-dependent) optimization of the powertrain energy management strategy (EMS). It yields optimal EMS outputs depending on the hybrid architecture, e.g., engine torque and gear ratio for AMT-equipped parallel hybrids, engine torque and speed for series hybrids, etc. The optimization criterion is the minimization of fuel consumption, or a combination of fuel consumption and pollutant emissions. A global constraint is applied to the battery state of charge, which has to fulfill a certain target value at the end of the drive cycle, depending on whether the operation is charge sustaining (autonomous hybrids) or charge depleting (plug-in hybrids).

HOT requires backward-facing quasistatic models of the powertrain components, which are generated as described in section 2, including their physical and operational limits. Drivability constraints can be added to improve the 
representativeness of the results, provided that they are mathematically formulated.

To solve the associated optimal control problem, HOT adopts the direct solution of Pontryagin's Minimum Principle equations. The main advantage over Dynamic Programming (Bellman algorithm) is that the resulting formulation can be implemented with only slight changes and no causality modifications as an online energy management strategy, embedded in a real-time powertrain supervisory controller $[15,16]$.

\section{First Results}

\subsection{Vehicles characteristics}

The sizing method enabled us to specify our different vehicles according to the Program of Demand. Table 2 indicates the vehicles characteristics for the three hybrids considered together with the reference vehicle.

Table 2: Vehicles and drivetrains specifications

\begin{tabular}{|c|c|c|c|c|}
\hline \multirow{2}{*}{$\begin{array}{l}\text { Vehicle and } \\
\text { drivetrain } \\
\text { specifications }\end{array}$} & \multicolumn{4}{|c|}{ Type of drivetrain } \\
\hline & Reference & HEV CS & $\begin{array}{l}\text { PHEV } \\
15 \mathrm{~km}\end{array}$ & $\begin{array}{l}\text { PHEV } \\
30 \mathrm{~km}\end{array}$ \\
\hline Overall mass $(\mathrm{kg})$ & 1200 & 1246 & 1322 & 1356 \\
\hline Load (kg) & \multicolumn{4}{|c|}{160} \\
\hline $\begin{array}{l}\text { Aerodynamic } \\
\text { S.Cx }(\mathrm{m} 2)\end{array}$ & \multicolumn{4}{|c|}{0.69} \\
\hline $\begin{array}{c}\text { Electric } \\
\text { auxiliaries (W) }\end{array}$ & 400 & \multicolumn{3}{|c|}{900} \\
\hline $\begin{array}{l}\text { IC engine max } \\
\text { power }(\mathrm{kW})\end{array}$ & 80 & 59 & 61 & 62 \\
\hline $\begin{array}{c}\text { Acceleration 0- } \\
100 \mathrm{kmh}(\mathrm{s})\end{array}$ & 12.4 & 11.1 & 10.3 & 10.3 \\
\hline \begin{tabular}{|l|} 
Electric machine \\
max power $(\mathrm{kW})$
\end{tabular} & & 25 & 35 & 35 \\
\hline $\begin{array}{c}\text { Acceleration 0- } \\
\text { 100kmh ESS } \\
\text { fully depleted (s) }\end{array}$ & & 17.8 & 18.1 & 18.2 \\
\hline $\begin{array}{l}\text { Battery peak } \\
\text { power }(\mathrm{kW})\end{array}$ & & 30 & 41 & 41 \\
\hline $\begin{array}{l}\text { Pack nominal } \\
\text { capacity (Ah) }\end{array}$ & & 6 & 20 & 40 \\
\hline $\begin{array}{l}\text { Pack nominal } \\
\text { Energy }(\mathrm{kWh})\end{array}$ & & 1.3 & 4.8 & 9.7 \\
\hline $\begin{array}{c}\text { Power to Energy } \\
\text { ratio }\left(\mathrm{h}^{-1}\right)\end{array}$ & & 23 & 8.5 & 4.3 \\
\hline $\begin{array}{l}\text { Pack nominal } \\
\text { voltage }(\mathrm{V})\end{array}$ & & 212 & 237 & 237 \\
\hline $\begin{array}{c}\text { Total battery } \\
\text { pack mass }(\mathrm{kg})\end{array}$ & & 33 & 89 & 123 \\
\hline $\begin{array}{l}\mathrm{E}_{\text {spe }} \text { pack } \\
(\mathrm{Wh} / \mathrm{kg})\end{array}$ & & 39 & 55 & 79 \\
\hline $\mathrm{P}_{\text {spe }}$ pack $(\mathrm{W} / \mathrm{kg})$ & & 908 & 460 & 333 \\
\hline
\end{tabular}

The difference in the acceleration performances between the reference vehicle and its hybridization, can be explain, as shown in Figure 2 by the oversizing of IC Engine components due to the velocity constraints in slope with a fully discharged ESS.

\subsection{Charge sustaining case}

As the vehicle is operated in CS mode and therefore only consumes gasoline, it was compared to the reference one according to three different types of uses (see Table 3). Comparison highlight the influence of the driving conditions on vehicle energy fluxes, especially :

- when the vehicle decelerates, the amount of energy available and recovered is high in urban conditions and decreases significantly to near zero on motorway;

- the IC engine working conditions are very severe for the conventional vehicle in urban conditions, resulting in a low average efficiency. As the IC engine working conditions improve on road and motorway type of use, the IC engine efficiency improves to reach $29 \%$ on motorway;

- the electric mode together with the assistance of the IC engine enables to reach a high efficiency on the IC engine for the types of use considered (34 to $35 \%$ )

Table 3: Vehicle simulation results

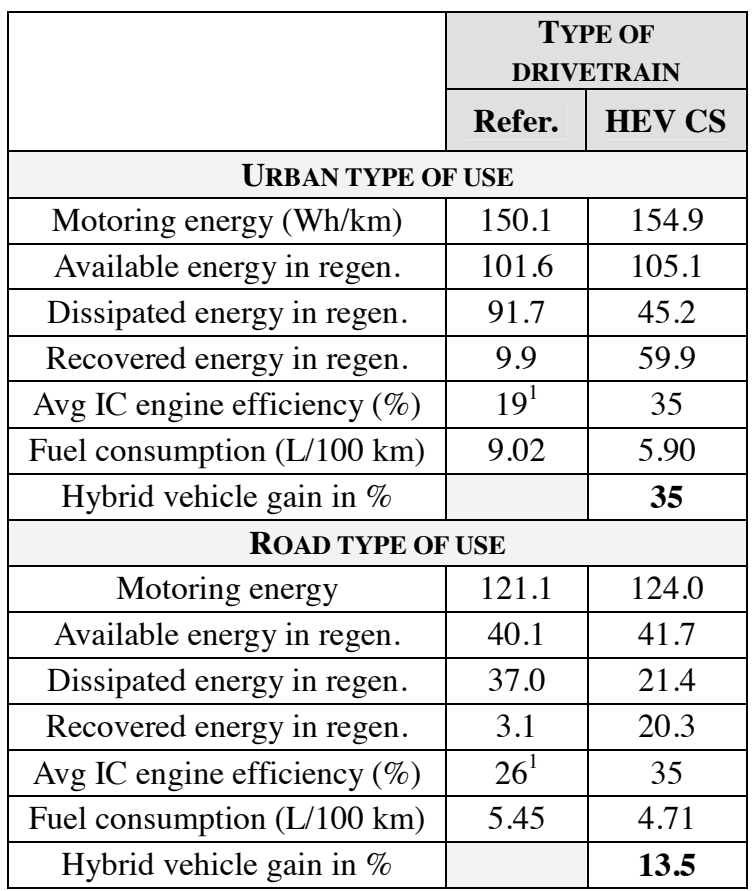




\begin{tabular}{|c|c|c|}
\hline \multicolumn{3}{|c|}{ МOTORWAY TYPE OF USE } \\
\hline Motoring energy & 178.7 & 181 \\
\hline Available energy in regen. & 22.1 & 23.1 \\
\hline Dissipated energy in regen. & 20.9 & 13.6 \\
\hline Recovered energy in regen. & 1.2 & 9.5 \\
\hline Avg IC engine efficiency (\%) & $29^{1}$ & 34 \\
\hline Fuel consumption (L/100 km) & 7.11 & 7.02 \\
\hline Hybrid vehicle gain in \% & & $\approx \mathbf{0}$ \\
\hline
\end{tabular}

Consequently, the figures reflect a well known characteristic of charge sustaining HEV with a FC gain which decreases significantly from urban to motorway conditions (resp. 35\%, $13 \%$ and near zero).

\subsection{Charge depleting case}

\subsubsection{Evaluation of the all electric range}

The evaluation of our Urban Capable PHEV AER was carried out on an urban cycle. Figure 3 illustrates the SOC variation and IC engine use, one could note that the $\mathrm{CD}$ range is higher than the AER, this is due to the limitation appearing in the battery discharge power at low SOC. The use of the IC engine would then be required for dynamic purpose in a blended mode during the final part of the $\mathrm{CD}$ phase.

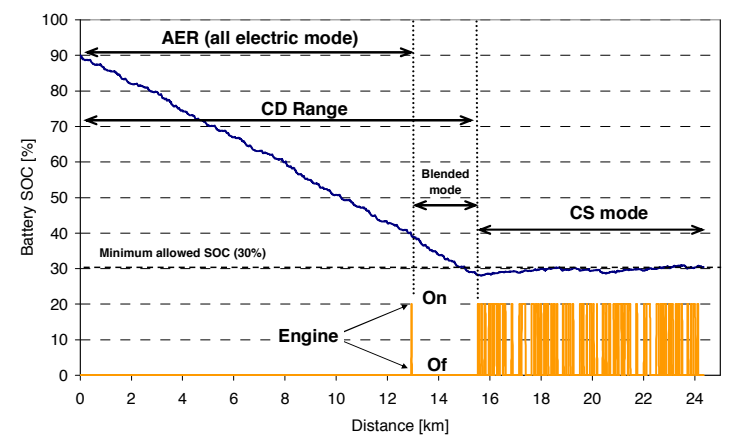

Figure 3: Battery SOC variations and IC engine operation during the urban cycle range evaluation for the $5 \mathrm{kWh}$ PHEV case

The All Electric Range has been evaluated for the two PHEVs vehicles (with 5 and $10 \mathrm{kWh}$ battery).Table 4 summarizes the distance which can be covered in the different phases for our two PHEVs, which according to their AE range may be called PHEV13 and PHEV23.

Table 4: Vehicle ranges in urban use

\begin{tabular}{|c|c|c|}
\hline Battery nominal energy $[\mathbf{k W h}]$ & $\mathbf{4 , 8}$ & $\mathbf{9 , 7}$ \\
\hline AER $[\mathrm{km}]$ & 13.0 & 23.0 \\
\hline CD range $[\mathrm{km}]$ & 15.0 & 29.0 \\
\hline
\end{tabular}

\footnotetext{
${ }^{1}$ IC engine efficiency considering the auxiliaries' loads
}

\subsubsection{Transfer from petroleum to electricity}

While the vehicle is operated, the Energy Management Strategy presented above enables to perform a progressive depletion of the battery. Changing the parameter value in the EMS will allow us to modify the rate of energy transfer, as highlighted in Figure 4 where fuel consumption is plotted according to electricity consumption for the 3 different driving conditions.

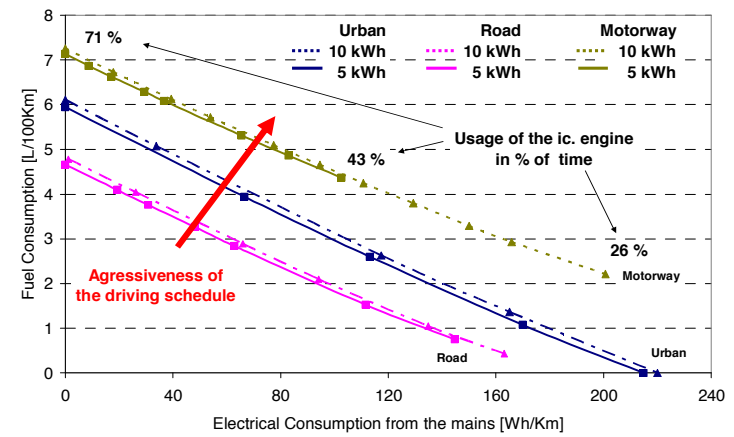

Figure 4: Variation of fuel consumption according to electric consumption

Some comments may be made from this figure, i.e.:

- the expression of FC vs. Electric Consumption is almost linear on a large part of the range;

- the curves for PHEV13 and PHEV23 appears to be very close for each cycle, as vehicle mass differs only due to the battery pack extra weight which is limited (see Table 2);

- the curves are ordered in accordance with a criterion expressing the overall energy consumption per kilometer for each cycle. This criterion may reflect the aggressiveness of the driving cycles;

- the progressive energy transfer from petroleum to electricity is achieved thanks to a decrease in the IC engine use, as illustrated for the motorway case;

- the minimum FC reachable on these specific driving patterns is a function of (i) the amount of energy in the battery, (ii) the distance covered and (iii) the maximum motoring power required, as the vehicles are operated in the blended mode;

- our two Urban Capable PHEV are able to cover the entire urban driving cycle without the help of the IC engine, as requested in their definition. The vehicle may then be operated in all electric mode with zero FC, which is not the case for the 2 other driving schedules; 
- simulations were carried out on driving cycles with variables distances (see Table 1), that should be taken into account in the comparison that could be made between the cycles, as far as battery energy is concerned;

\subsubsection{Daily use of the vehicle}

All the vehicles have been evaluated on the daily $40 \mathrm{~km}$ mission (mission1) defined in chapter 3.1. Figure 5 illustrates the battery SOC variations for the HEV CS and the PHEV13 with and without the $\mathrm{ZEV}$ requirement on the urban part of the trip. It is important to note that in this last case the optimization provided by the EMS can't be followed due to the ZEV constraints. Indeed, the SOC value at the beginning of the ZEV part has been set in order to have a progressive discharge of the battery with the aim to compromise ageing and dynamic performances.

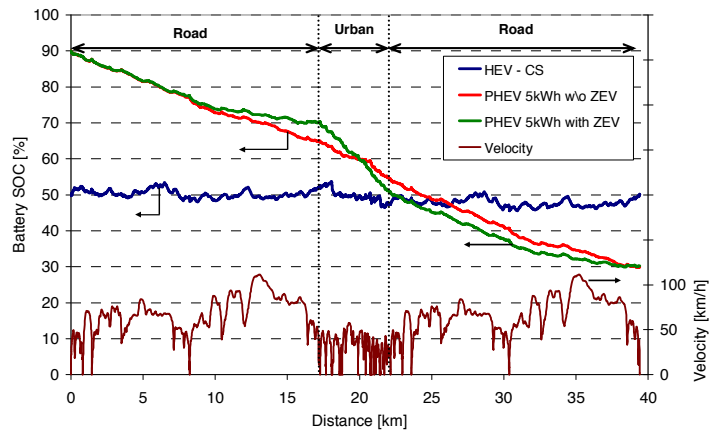

Figure 5: Battery SOC variations on daily use case for different management hypothesis

For the CD case evaluation, an energy transfer ratio shall be defined. This ratio represents the energy displacement from the fuel to the electricity vector provided by the grid while recharging the battery.

$$
r_{\text {transfer }}=\frac{E_{\text {grid }}}{E_{\text {grid }}+E_{\text {fuel }}}
$$

The results are summarized in the Table 5, one could note:

- a progressive energy displacement from gasoline to electricity, reaching up to $80 \%$ with the $10 \mathrm{kWh}$ battery (PHEV23) for this $40 \mathrm{~km}$ daily trip. The consequence on the gasoline consumption is very important with a decrease up to a factor of 10 in our specific case;

- the relatively low influence of the urban ZEV requirement on the energies consumption. This is particularly true for the PHEV23, where the optimal energy strategy on the mission gives the same results as the suboptimal energy management constrained to ZEV on the urban part of the trip. In the PHEV13 case the extra fuel consumption due to the suboptimal energy management is only $2 \%$.

Table 5: Vehicles energies consumptions on the daily mission 1

\begin{tabular}{|c|c|c|c|}
\hline \multirow[t]{2}{*}{$\begin{array}{c}\text { Type of } \\
\text { drivetrain }\end{array}$} & $\begin{array}{l}\text { Fuel } \\
\text { Cons. }\end{array}$ & $\begin{array}{l}\text { Elect. } \\
\text { Cons. }\end{array}$ & $\begin{array}{c}\text { Energy } \\
\text { transfer } \\
\text { ratio }^{2}\end{array}$ \\
\hline & $\mathrm{L} / 100 \mathrm{~km}$ & Wh/km & $\%$ \\
\hline $\begin{array}{l}\text { Reference } \\
\text { vehicle }\end{array}$ & 5.89 & & \\
\hline HEV CS & 4.87 & & \\
\hline $\begin{array}{c}\text { PHEV13 wlo } \\
\text { ZEV }\end{array}$ & 2.44 & 82.8 & 27 \\
\hline $\begin{array}{c}\text { PHEV13 with } \\
\text { ZEV }\end{array}$ & 2.48 & 82.5 & 27 \\
\hline $\begin{array}{c}\text { PHEV23 wlo } \\
\text { ZEV }\end{array}$ & 0.46 & 167.5 & 80 \\
\hline $\begin{array}{c}\text { PHEV23 with } \\
\text { ZEV }\end{array}$ & 0.46 & 167.5 & 80 \\
\hline
\end{tabular}

In order to access the influence of the daily distance covered, the case of a commuter driving $80 \mathrm{~km}$ has been considered (mission 2). Results are presented in Table 6 . One could note that, as compared to the $40 \mathrm{~km}$ daily mission, the depleted amount of energy from the battery will then be diluted in a distance 2 times greater. As a consequence, the transfer ratio will be significantly reduced, and consequently the benefit from the PHEV concept. The maximum gasoline consumption decreases for our PHEV case by a factor of 2 , which is certainly not negligible but lower than the former case.

Table 6: Vehicles energies consumptions on the daily mission2

\begin{tabular}{|c|c|c|c|}
\hline $\begin{array}{c}\text { Type of } \\
\text { drivetrain }\end{array}$ & $\begin{array}{c}\text { Fuel } \\
\text { Cons. }\end{array}$ & $\begin{array}{c}\text { Elect. } \\
\text { Cons. }\end{array}$ & $\begin{array}{c}\text { Energy } \\
\text { transfer } \\
\text { ratio }\end{array}$ \\
\cline { 2 - 4 } & L/100km & Wh/km & \% \\
\hline $\begin{array}{c}\text { Reference } \\
\text { vehicle }\end{array}$ & 5.68 & 44.5 & 12 \\
\hline HEV CS & 4.79 & 43.7 & 12 \\
\hline $\begin{array}{c}\text { PHEV13 wlo } \\
\text { ZEV }\end{array}$ & 3.45 & 8.50 & 30 \\
\hline $\begin{array}{c}\text { PHEV13 with } \\
\text { ZEV }\end{array}$ & 2.30 & 89.1 & 30 \\
\hline $\begin{array}{c}\text { PHEV23 wlo } \\
\text { ZEV }\end{array}$ & 2.32 & 89.2 & \\
\hline $\begin{array}{c}\text { PHEV23 with } \\
\text { ZEV }\end{array}$ & & & \\
\hline
\end{tabular}

\footnotetext{
2 as defined in Eq. (1)
} 
This simulation on two different types of daily trips has highlighted the fact that, if the variation on FC benefit are minor for the HEV CS case (resp. 17,3 and 15,7\%) the impact of the daily driven distance on the PHEV energies consumptions may be very important.

\section{Conclusion}

We have presented in this paper a method developed at IFP Energies nouvelles and dedicated to the component sizing for different HEVs operated in charge sustaining and depleting in a blended mode. An analysis of the vehicle energy consumption(s) has been carried out for various types of use.

The results highlight the fact that for the charge sustaining case the fuel consumption gain is very sensitive to vehicle use, with a maximum of $35 \%$ in urban condition and almost zero on motorway conditions.

For the plug-in HEV case, our results indicate that a very significant fuel consumption decrease may be obtained if the vehicle is operated on a distance which is close to its charge depleting range. To illustrate this, on the $40 \mathrm{~km}$ daily trip, our PHEV with a $10 \mathrm{kWh}$ battery and a $29 \mathrm{~km}$ CD range may displace up to $80 \%$ of its energy consumption from gasoline to electricity, resulting in a FC divided by a factor of more than 10 as compared to our reference vehicle (see Table 5).

However simulation results indicated that for a smaller battery case $(5 \mathrm{kWh}, 15 \mathrm{~km}$ CD range) or a longer daily distance $(80 \mathrm{~km})$, the energy transfer ratio may fall quickly to very low values (12 to 30\%), with consequently lower FC benefit, a factor of more than 2 is all the same maintained, which is not negligible.

Another fact to point out is the ability of our PHEVs to operate in all electric range in the central part of the trip with no local pollutant emission values.

These results illustrate the very high potential impact, of PHEVs and the difficulty in the vehicle drivetrain sizing. The goal of the future owner being to match the sizing, and especially the CD range, with its expected use, the objective being to get the maximum benefit for a minimum extra cost in the vehicle retail price and maintenance.

However our methodology is still improving and the on going research axes will focus on:
- the component simulation and testing, with the aim to take into account as best as possible the effect of their sizing on their efficiency and dynamic behavior (IC engine, battery and electric machine especially);

- the effect of the specific PHEV battery operation (SOC window, charging...) on the battery ageing. Specific PHEVs battery working conditions provided by the simulations may constitute a precious input for the knowledge and prediction of battery ageing;

- the influence of our 'off line' energy management laws could be compared with 'on line' ones that would be closer to the operation of the vehicle in real cases;

Another major research axe is the focus on the life cycle analysis in order to access the green house gas (GHG) and pollutant emission values related to the electricity production. This is of primary importance in order to set up a complete energy pollution balance for PHEVs, taking into account the electricity production.

\section{References}

[1] E.D. Tate et.al., The Electrification of the Automobile: From Conventional Hybrid, to Plug-in Hybrids, to Extended-Range Electric Vehicles, SAE Technical paper 2008-01-0458.

[2] M. Andre, The ARTEMIS European driving cycles for measuring car pollutant emissions, Science of the Total Environment, 2004, Vol. 334-335, p. 73-84.

[3] A. Delorme et.al., Fuel Economy Potential of Advanced Configurations from 2010 to 2045, Proceedings Les Rencontres Scientifiques de l'IFP - Advances in Hybrid Powertrains; 25-26 November 2008.

[4] T.Q. Duong, Emerging Battery Technologies, PLUG-IN 2008, A Short Drive to Tomorrow, San Jose, California, July 23, 2008.

[5] A. Chu, Next generation automotive class prismatic cells and systems, AABC 2009.

[6] A. Delorme et.al., Cost Benefit Analysis of Advanced Powertrains from 2010 to 2045, EVS24, Stavanger, Norway, May 13-16, 2009.

[7] V. Sauvant-Moynot et.al., An integrated approach to high-power battery modeling: from the electrochemistry to the vehicle, EVS24, Stavanger, Norway, May 13-16, 2009.

[8] A. Sciarretta et.al., Advances in model-based SoC determination for HEV traction batteries, 
AEA 2008, 4th European Conference on Alternative Energies for the Automotive Industry, Poitiers France April 2008

[9] F. Badin, Modeling of on-board Energy Storage System ageing, the French SIMSTOCK research network, EVS24, Stavanger, Norway, May 1316, 2009.

[10] J. Bernard et.al., Advances in electrochemical models for predicting the cycling performance of traction batteries: experimental study on $\mathrm{Ni}$ $\mathrm{MH}$ and simulation, Proceedings Les Rencontres Scientifiques de l'IFP, IFP Energies nouvelles, Rueil-Malmaison, France, 25 - 26 November 2008.

[11] F. Badin et.al., Hybrid drive trains evaluation in actual use, Electric Vehicle Symposium n ${ }^{\circ} 13$, Osaka Japon, Octobre 1996.

[12] F. Badin et.al., The potential for fuel consumption reduction, from Stop-Start to Plugin HEVs in actual use, SAE Hybrid Vehicle Technologies 2007 symposium, San Diego USA, February 2007.

[13] M. Ehsani et.al., Modern electric, hybrid electric, and fuel cell vehicles: Fundamentals, Theory and Design, ISBN 0-8493-3154-4, CRC Press.

[14] A.E. Fuhs, Hybrid vehicles and the future of personal transportation, ISBN 978-1-42007534-2, CRC Press.

[15] A. Chasse et.al., Online Implementation of an Optimal Supervisory Control, for a Parallel Hybrid Powertrain, SAE Technical paper 200901-1868, 2009.

[16] A. Sciarretta et.al., Control of hybrid electric vehicles. Optimal energy-management strategies, Control Systems Magazine, vol. 27, no. 2, April 2007, p. 60-70.

\section{Authors}

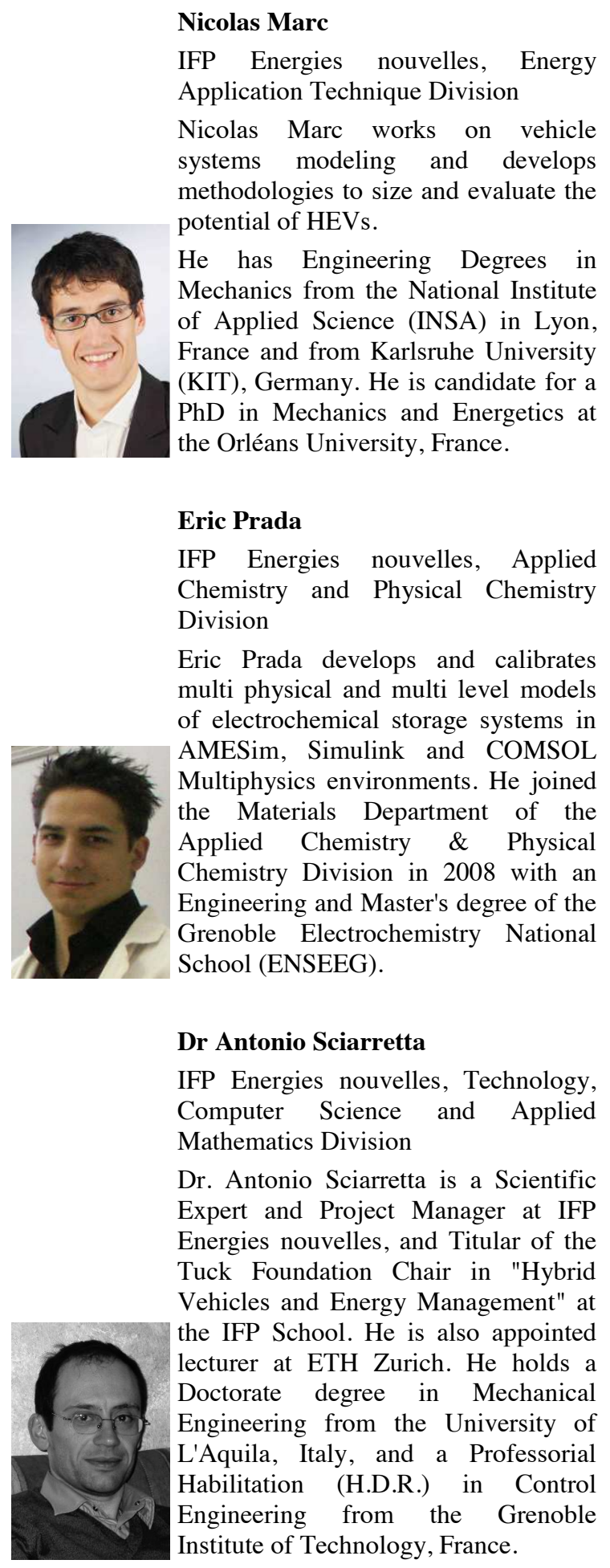




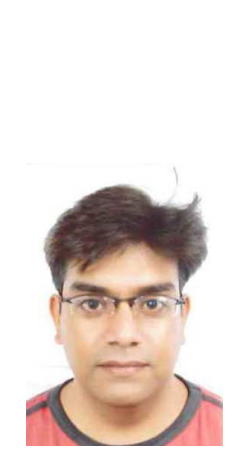

\section{Shadab Anwer}

IFP Energies nouvelles, IFP School

Shadab Anwer is a graduated from Indian Institute of Technology Kanpur (IITK), India in Mechanical Engineering (2009). Currently, he is doing Masters in Powertrain Engineering at IFP School, Paris and working at IFP Energies nouvelles (Solaize) on Energy management strategies and performance evaluation of Hybrid Powertrains.

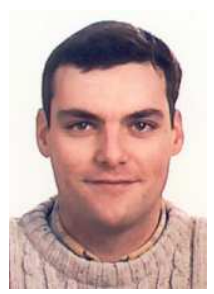

\section{Franck Vangraefschepe}

IFP Energies nouvelles, Energy Application Technique Division

Franck Vangraefschepe is working since ten years at IFP Energies nouvelles. He is now project manager in the thematic Vehicle electrification.

\section{Dr François Badin}

Expert Director Hybrid Vehicles

IFP Energies nouvelles, Energy Application Technique Division

François Badin was a researcher at the INRETS for 22 years, he was senior researcher, in charge of electric and hybrid vehicle activities. F. Badin joined IFP Energies nouvelles in February 2008 as a senior expert in hybrid vehicle activities. François Badin has a Scientific Doctorate in Environmental Engineering from the University of Chambéry, France and a five-year Engineering Degree in thermo-dynamic processes from the National Institute of Applied Sciences (INSA) in Lyon, France.

\section{Dr Alain Charlet}

PRISME/EPM - Université d'Orléans

Alain Charlet is a associate professor at the University of Orléans in the Vehicle and Energy Systems department of Polytech'Orléans. He is member of the Engine Research Group (EPM) of the PRISME laboratory of the University of Orléans. His research topics are in the field of internal combustion engines covering combustion, energy conversion, energy management, exhaust gas aftertreatment and engine control.

\section{Pr Pascal Higelin}

PRISME/EPM - University of Orléans

Pascal Higelin is a full professor at the University of Orléans in the Vehicles and Energy Systems department of Polytech'Orléans since 2004. His is currently heading the engine research group (EPM) of the PRISME laboratory of the University of Orléans. His research topics are in the field of internal combustion engines covering combustion, energy conversion, energy management, exhaust gaz after-treatment and engine control. His focus is mainly on the optimization of new concepts of high efficiency and low emissions internal combustion engines 